\title{
Plasma Testosterone in Fetal Rats and Their Mothers on Day 19 of Gestation
}

\author{
E. J. HOUTSMULleR, ${ }^{* 1}$ F. H. DE JONG,* D. L. ROWLAND $\dagger$ AND A. K. SLOB* \\ *Department of Endocrinology and Reproduction, Faculty of Medicine and Health Sciences, Erasmus University \\ Rotterdam, P.O. Box 1738, 3000 DR Rotterdam, The Netherlands, and †Department of Psychology, \\ Valparaiso University, Valparaiso, IN 46383 USA
}

Received 12 July 1993

\begin{abstract}
HOUTSMULLER, E. J., F. H. DE JONG, D. L. ROWLAND AND A. K. SLOB. Plasma testosterone in fetal rats and their mothers on day 19 of gestation. PHYSIOL BEHAV 57(3) 495-499, 1995. - Plasma testosterone levels were higher in pooled samples from male fetuses than from female fetuses on day 19 of pregnancy. Plasma testosterone from female fetuses with males located caudally in the uterus was higher than from females that lacked such males. Testosterone level of both male and female fetuses was correlated with maternal testosterone. No correlation was found between maternal testosterone and number of males in the litter, male-to-female ratio, or litter size. These results corroborate earlier findings of a sex difference in plasma testosterone levels on fetal day 19 in rats, and provide support for the hypothesis that female rats receive androgens from males located caudally in the uterus. No evidence was found that testosterone of pregnant females is affected by the sex ratio or size of her litter.
\end{abstract}

Testosterone Prenatal Sexual differentiation Intra-uterine position
Rat Female

\section{INTRODUCTION}

THERE is considerable variation among normally developed female rats in the frequency with which they display masculine sexual behavior (mounting) in adulthood. Since perinatal androgens are important for the organization of this behavior (see 2), it has been suggested that this variation among females stems from variation in the arnount of prenatal androgen exposure. Indeed, detectable testosterone levels have been found in female fetuses, and these levels differ substantially among individuals $(3,21,36)$. Since there is no evidence to suggest that female fetuses themselves produce androgen, the question arises as to the source of this testosterone. Several studies have shown that the placenta produces androgen (e.g., 10,15). In addition, the ovaries (25) of the mother, and male fetuses sharing the same uterine horn (7) have been suggested as possible sources.

While evidence purporting an influence of androgens from male uterine mates has been offered in a number of studies (e.g., rats: $7,18,26$, but see also 23,27 ; mice: $30,31,36,37$ ), there is uncertainty about the mechanism through which such androgens might actually reach female fetuses in utero. Diffusion through the amniotic sac to adjacent females (i.e. adjacent male effect, 7), and transport of androgens via the vasculature to females from males located caudally (i.e., caudal male effect, 18) have both been proposed as possible mechanisms. In rats, studies have indirectly (i.e., based upon sexual differentiation), but preferentially, supported a caudal male effect. Both females and males having caudal males in utero show greater morphological masculinization at birth and behavioral masculinization in adulthood than same-sex siblings without caudal males $(1,12-14,20)$.

Despite evidence based upon sexual differentiation studies, evidence that prenatal testosterone levels actually differ between female fetuses occupying different uterine positions is scant and inconclusive. In mice (32) and gerbils (5), prenatal testosterone level is reportedly higher in females with two adjacent males than in females without adjacent males. In ferrets, higher testosterone has been found in females with two caudal males than in females with one or none (17). In hamsters, androgen levels were lower and estradiol levels elevated in males with females located caudally (29). Yet in fetal rats there is no evidence from hormone studies that testosterone levels differ in any systematic way between females from different uterine positions. Baum et al. (3) analyzed androgen levels (total androgen in entire body) of female fetuses, but failed to find support for androgen transport between fetuses. However, in that study the number of animals included for testosterone analysis specifically on days 18 and 19 of gestation was small (i.e., 3,2 and 15 with 0,1 and $>1$ caudal male, respectively). The sex difference in prenatal androgen level of rats is most profound on days $18 / 19$ of gestation, the result of a sharp transient increase in fetal males that is critical to their behavioral masculinization $(3,21,36)$. It is possible that the lack of effect seen in the study by Baum et al. (3) resulted from the limited group sizes on these critical gestational days. Therefore,

\footnotetext{
${ }^{1}$ Requests for reprints should be addressed to E. J. Houtsmuller, Department of Biological Sciences, University of Notre Dame, Notre Dame, IN 46556. E-mail: Elisabeth.J.Houtsmuller.2@nd.edu
} 
TABLE 1

MEAN ( \pm SE) PLASMA TESTOSTERONE OF FETAL RATS (POOLED SAMPLES) AND THEIR MOTHERS (INDIVIDUAL SAMPLES)

\begin{tabular}{llc}
\hline & $n$ & $\begin{array}{c}\text { Plasma testosterone level } \\
(\mathrm{nmol} / \mathrm{)})\end{array}$ \\
\hline Mothers & 20 & $2.5 \pm 0.11$ \\
Male fetuses & 40 & $2.8 \pm 0.18$ \\
Female fetuses & 40 & $1.0 \pm 0.15^{*}$ \\
$\quad$ with caudal males & 28 & $1.1 \pm 0.20$ \\
without caudal males & 12 & $0.7 \pm 0.15 \dagger$ \\
\hline
\end{tabular}

${ }^{*} p<.01$, compared to male fetuses; $\uparrow p=.05$, compared to female fetuses with caudal males.

the first purpose of the present study was to reexamine whether female fetuses with caudal males have higher testosterone levels, specifically on day 19 of pregnancy, than female fetuses without caudal males.

While much research has focussed on the influence of androgens from male uterine mates, other androgen sources may also contribute to prenatal masculinization of female rats. For example, there appear to be differences in masculinization of females across all-female litters. That is, females from an all-female litter born to one dam may show overall higher levels of masculine sexual behavior in adulthood in comparison with females from all-female litters born to another dam (Houtsmuller et al., unpubl. observations). Such variation between all-female litters cannot be attributed to male uterine mates, as all such females lack prenatal exposure to androgens from males fetuses. Since pregnant rats show considerable differences in blood levels of androgens (10), and since testosterone administration to pregnant females results in increased masculinization of female offspring (e.g., $9,22,34$ but see also 16), differences in endogenous androgen among pregnant females may account for some variation in masculinization of female offspring born to different mothers. Therefore, the second purpose of the present study was to determine whether testosterone level of maternal blood was related to that of female fetuses.

Finally, male fetuses themselves may be an important source of androgen in pregnant females, as is known to be the case in the rhesus monkey (19). A recent report indicates significant correlations in gerbils between number and proportion of males in a litter, and testosterone in maternal blood (6). Specifically, the higher the number of males in the litter, the higher the maternal androgen level, suggesting that male fetuses contribute significantly to androgen levels in maternal circulation. Since androgens in maternal blood may in turn influence masculinization of fetuses, male fetuses could affect female fetuses indirectly via the maternal circulation. Therefore, the third purpose of the present study was to investigate the relationship between testosterone level in maternal blood as well as that in female fetuses on the one hand, and several litter parameters, such as number of males, number of females, male-to-female ratio, and litter size on the other.

\section{METHODS}

Twenty-one Wistar females (TNO, Zeist), housed 2-3 to a cage and kept on a 12-12 h light schedule, were mated in our laboratory. On day 19 of pregnancy (day of impregnation $=$ day 0 ), blood from the mother was collected from the orbital plexus under light ether anaesthesia. Immediately thereafter, caesarean section was performed by making a midline incision in the ab- domen. The two uterine horns were spread out, and pups were removed from the horns and laid out according to their uterine position. Blood from fetuses was collected through an incision in the carotid artery and vein. Blood was collected from 106 female fetuses, 114 male fetuses and 21 mothers. One female appeared not to be pregnant and was excluded from the analysis.

Blood from mothers was assayed individually. Blood from individual fetuses was insufficient for measurement of hormones, so samples were pooled. Because of the high number of females per litter, several pooled samples were typically obtained from a single litter. In total, there were 20 litters, from which 40 pooled samples of female fetuses and $\mathbf{4 0}$ of male fetuses were obtained. Number of fetuses per pooled sample ranged from $1-4$ (mean $=$ 2.3 ) for females and $1-5$ (mean $=2.8$ ) for males.

Blood from female fetuses was pooled on the basis of uterine position: either the presence of absence of caudal males, or for some pools, the actual number of caudal males. Blood was pooled from females within the same litter, with one exception. In the latter case, blood was pooled from females from two litters, but these female fetuses occupied the same position regarding the caudal male classification. Blood from male fetuses was pooled from males in the same litter, irrespective of their position in utero.

\section{Hormone Measurements}

Testosterone levels were estimated in plasma by a radioimmunological method (28) in which $5 \alpha$-dihydrotestosterone crossreacts for $43.2 \%$. Inter- and intraassay coefficients of variation were $13.4 \%$ and $5.6 \%$, respectively.

\section{Data Analysis}

Student's $t$-test was used to test for a sex difference in fetal testosterone level, and to test the caudal male hypothesis. To test the caudal male hypothesis, pooled samples from female fetuses with caudal males $(n=28)$ were compared with those from females without caudal males $(n=12)$.

In addition to the comparison regarding the presence of caudal males, testosterone levels were correlated with several variables. To this end, samples were classified according to various relevant variables other than the mere presence of caudal males. These variables included: number of caudal males, number of rostral males, number of males in the same uterine horn, number of males in the entire litter and male-to-female sex ratio. Thus, fetal pools were repeatedly recategorized, according to each of these different variables. For example, a correlation was run between testosterone level of female fetuses and the number of males in the litter, regardless of the number of caudal males.

Because pooled samples did not always qualify for all variables, the number of samples was different when testing different relationships. For example, a sample may have contained blood from 3 females from one uterine horn, all of whom had caudal males, but who differed on the exact number of caudal males. This pooled sample would consequently be included in correlations with the number of males in the same uterine horn and maternal testosterone, but would be excluded from the correlation with the number of caudal males. Furthermore, any correlations including matemal testosterone did not include the pooled sample from two different litters. Correlations were performed using the Spearman test as not all variables were normally distributed.

Testosterone levels were also correlated between pooled samples of females coming from the same litter to determine whether pools drawn from the same mother tended to have similar levels 
of testosterone. Thus, the influence of factors affecting the litter as a whole, rather than specific individuals, could be determined.

Consistent with theoretical expectations, one-tailed tests were used to determine caudal male effects. For all other analyses, two-tailed $p$ values are reported.

\section{RESULTS}

Testosterone levels lere lignificantly higher in male than in female fetuses $(p<.01)$ (Table 1$)$.

\section{Testosterone of Female Fetuses and the Presence of Caudal Males}

The plasma testosterone level of females with caudal males in the uterine horn was significantly higher than that of females without such males $(p=.05)$ (Table 1). In addition, testosterone levels of females correlated significantly with the number of caudal males in the same uterine horn (0 to 4) (Table 2).

Testosterone level of female fetuses correlated positively, although not significantly, with the number of males in the same uterine horn. In addition, for female samples, the number of caudal males correlated with the overall number of males in that uterine horn $(r=.44 ; p=.01)$. These two relationships suggest that the correlation between testosterone level and the number of caudal males may have occurred because of an effect from the overall number of males in the same uterine horn, rather than specifically from caudal males. To eliminate this possibility, the correlation between female fetal testosterone level and the number of rostral males was also calculated: testosterone level of females was not signficantly correlated with the number of rostral males (Table 2).

\section{Fetal Testosterone, Maternal Testosterone and Sex Composition of the Litter}

Testosterone levels of both female and male fetuses were positively correlated with maternal testosterone level (Table 2). No relationships between sex composition of the litter and testosterone levels of fetuses or mother were found, that is, between number of males in the entire litter, male-to-female ratio, or littersize on the one hand, and plasma testosterone level in female fetuses, in male fetuses, or in maternal blood on the other. Testosterone level of female fetuses was significantly correlated with testosterone level of female siblings, and testosterone level of males was marginally correlated with testosterone level of male siblings.

\section{DISCUSSION}

The present study confirms earlier reports which have shown that in fetal rats, testosterone content is significantly higher in males than in females on day 19 of gestation $(3,21,36)$. This study also provides evidence for the first time that female rat fetuses that develop in utero with male siblings located caudally have higher testosterone levels on day 19 of gestation than females that lack such males. Furthermore, in female fetuses, a higher number of caudal males is associated with a higher testosterone level. Previous experiments have provided evidence that female rats with caudal males in utero are more masculinized than females without caudal males, both in genital morphology at birth (i.e., anogenital distance, an androgen-sensitive measure) and in masculine sexual behavior in adulthood $(12,14,18,20)$. Although it has long been assumed that this increased masculinization in females having caudal males is due to exposure to higher levels of androgens prenatally (18), the present study provides positive evidence for such an increase in prenatal testosterone level in this
TABLE 2

CORRELATIONS AMONG MATERNAL (INDIVIDUAL SAMPLES) AND FETAL (POOLED SAMPLES) TESTOSTERONE AND VARIABLES RELATED TO THE UTERINE ENVIRONMENT.

\begin{tabular}{lcccccc}
\hline & \multicolumn{5}{c}{ Plasma Testosterone Levels } \\
\cline { 2 - 7 } & $\begin{array}{l}\text { Female } \\
\text { Fetuses }\end{array}$ & $n$ & $\begin{array}{c}\text { Male } \\
\text { Fetuses }\end{array}$ & $n$ & Mothers & $n$ \\
\hline Number of caudal males & $.35 \dagger$ & 30 & & & \\
$\begin{array}{l}\text { Number of rostral males } \\
\text { Number of males in }\end{array}$ & -.02 & 24 & & & \\
$\quad$ uterine horn & .24 & 30 & & & & \\
$\begin{array}{l}\text { Maternal testosterone } \\
\text { Testosterone same-sex }\end{array}$ & $.26 *$ & 40 & $.39 \dagger$ & 40 & & \\
$\quad$ siblings & $.39 \dagger$ & 33 & $.29 \ddagger$ & 33 & & \\
$\begin{array}{l}\text { Number of males in } \\
\quad \text { both horns }\end{array}$ & .13 & 40 & -.11 & 40 & -.18 & 20 \\
$\begin{array}{l}\text { Male/female ratio } \\
\text { Litter size }\end{array}$ & .19 & 40 & -.21 & 40 & .08 & 20 \\
\hline
\end{tabular}

${ }^{*} p<.05 ; \ddagger p<.01 ; \ddagger p=.06$.

group. This finding is in accordance with an earlier study reporting higher testosterone levels in female ferrets with two caudal males than in females with one or no caudal male (17), but contradicts another study (3) in which no difference was found in androgen levels of female rat fetuses with and without caudal males. In this latter study (3), Baum and his coworkers measured androgens on days $17-22$ of gestation, whereas in the present study testosterone was measured specifically on day 19 . Since several reports have suggested that the greatest sex difference in testosterone prenatally is restricted to days 18 and 19 , due to a sharp increase in testosterone in male fetuses on these days $(3,11,36$, although sex differences on other days of gestation have been reported as well, 21), the difference between females with and those without caudal males may be apparent only on these two days. Although androgen measured in fetuses on days $18 / 19$ was analyzed separately from other gestational days by Baum et al. (3), the subgroup for days $18 / 19$ was small. Our ability to detect a difference in androgen on day 19 between females with and without caudal males may have resulted from our larger sample size. Nonetheless, while the present study supports an effect for caudal males on female androgenization, the physiological mechanism underlying the transport of these androgens to females remains unclear (e.g., see 8).

Although the correlation between testosterone levels of female fetuses and number of caudal males was statistically significant, only about $12 \%\left(r^{2}\right)$ of the variance in testosterone level of female fetuses was explained by the number of caudal males. A partial explanation for this low covariance is that, like the group with caudal males, the group lacking caudal males also had remarkably high testosterone levels. This general idea is consistent with behavioral observations, which show that some females without caudal males in utero may show high levels of masculine sexual behavior in adulthood, suggesting substantial prenatal masculinization $(12,18)$ independent of caudal males. Thus, while caudal males may increase masculinization of females, their presence accounts for only part of the masculinization of females.

Testosterone level of female fetuses was significantly correlated with that of female siblings, suggesting less variation of testosterone within litters than across litters. Strong variation across litters in morphological masculinization of females (i.e., 
anogenital distance) has also been reported in mice (38). Together, these findings suggest that in addition to factors which androgenize specific individuals in the uterus (e.g., caudal males, placenta), there may also be significant factors affecting the litter as a whole (e.g., androgens in maternal blood). The present study attempted to specify the relevance of two such factors which might impact the litter as a whole: testosterone level in maternal circulation, and the number of males in the litter.

Regarding the former, small but significant positive correlations between testosterone level in maternal blood and that of both female and male fetal pools were found, suggesting that maternal blood is a possible source of androgens affecting the whole litter. While there remains some question regarding the extent to which maternal testosterone can impact behavioral masculinization of female fetuses $(16,22)$, it is commonly accepted that systemic testosterone administration to pregnant females results in behavioral masculinization of female offspring (e.g., 9,34 ), presumably through the transfer of androgens from maternal blood to fetal circulation.

Alternatively, it may be that the male fetus produces testosterone which in turn affects the androgen level of the mother, rather than vice versa. The placentas become an important source of androgen in maternal circulation between days $12-18$ of pregnancy (10). In addition, a recent report has suggested that testosterone level of pregnant gerbils increases with the number of males in the litter (6). Consistent with this finding, testosterone level in one nonpregnant female from the present experiment (excluded from the analysis) was considerably lower $(0.2 \mathrm{nmol} /$ 1) than that in pregnant females (mean:2.5 \pm .11 ). However, we found no significant correlations between maternal testosterone and overall number of males in the litter, male/female ratio, or litter size in these females. In this respect, our finding corroborates an earlier study (35) which also reported no significant cor- relation between number of males or litter size and testosterone in maternal blood in rats. Therefore, although the present study has established a relationship between maternal and fetal testosterone levels in the rat, and thus reiterates the importance of factors that might impact the litter as a whole, no definite conclusion can be drawn at this point regarding the direction of that relationship.

The present study found no evidence to support the idea that male fetuses influence plasma testosterone levels of all female fetuses equally within the litter, regardless of uterine position or horn, via the general maternal circulation. Were female fetuses affected by male fetuses mainly through general maternal circulation, a relationship between female fetal or maternal testosterone and the number or ratio of males might be expected. However, none of these variables were found to covary significantly.

In conclusion, the present study suggests that variation in testosterone level in female fetuses on day 19 of pregnancy can partly be explained by the presence or absence of caudal males. Furthermore, fetal testosterone level of both males and females correlated positively with maternal testosterone and mean testosterone of same-sex siblings, but no relationship was found between maternal testosterone and sex ratio of the litter or litter size. Further research needs to investigate the extent to which fetuses are affected by endogenous androgens in the maternal circulation, and to identify other factors that might affect the testosterone level of the litter as a whole. In addition, as caudal males accounted for only a small portion of the variance in testosterone, other potential sources of androgens which might affect individual fetuses within the uterus need to be investigated. For example, testosterone production by the placenta during the second half of pregnancy has been demonstrated (10), and several reports have identified the placenta as a major source of androgen in the female fetus $(24,33)$.

\section{REFERENCES}

1. Babine, A. M.; Smotherman, W. P. Uterine position and conditioned taste aversion. Behav. Neurosci. 89:461-466; 1984.

2. Baum, M. J. Differentiation of coital behavior in mammals: A comparative analysis. Neurosci. Biobehav. Rev. 3:265-284; 1979.

3. Baum, M. J.; Woutersen, P. J. A.; Slob, A. K. Sex difference in whole-body androgen content in rats on fetal days 18 and 19 without evidence that androgen passes from males to females. Biol. Reprod. 44:747-751; 1991 .

4. Clark, M. M.; Galef, B. G. Effects of uterine position on rate of sexual development in female mongolian gerbils. Physiol. Behav. 42:15-18; 1988

5. Clark, M. M.; Crews, D.; Galef, B. G. Concentrations of sex steroid hormones in pregnant and fetal mongolian gerbils. Physiol. Behav. $49: 239-243 ; 1991$

6. Clark, M. M.; Crews, D.; Galef, B. G. Androgen mediated effects of male fetuses on the behavior of dams late in pregnancy. Dev. Psychobiol. 29:25-35; 1993.

7. Clemens, L. G.; Gladue, B. A.; Coniglio, L. P. Prenatal endogenous androgenic influences on masculine sexual behavior and genital morphology in male and female rats. Horm. Behav. $10: 40-53 ; 1978$

8. Even, M.D.; Dhar, M.G.; Vom Saal, F.S. Transport of steroids between fetuses via amniotic fluid in relation to the intrauterine position phenomenon in rats. J. Reprod. Fert. 96:709-716; 1992.

9. Geral1, A. A.; Ward, I. L. Effect of prenatal exogenous androgen on the sexual behavior of the female albino rat. J. Comp. Physiol. Psychol. 62:370-375; 1966.

10. Gibori, G; Sridaran, R. Sites of androgen and estradiol production in the second half of pregnancy of the rat. Biol. Reprod. 24:249 $256 ; 1981$.
11. Hoepfner, B. A.; Ward, 1. L. Prenatal and neonatal androgen exposure interact to affect sexual differentiation in female rats. Behav. Neurosci. 102:61-65; 1988.

12. Houtsmuller, E. J.; Slob, A. K. Masculinization and defeminization of female rats by males located caudally in the uterus. Physiol. Behav. 48:555-560; 1990.

13. Houtsmuller, E. J.; Juranek, J; Gebauer, C; Slob, A. K.; Rowland, D. L. Males located caudally in the uterus affect sexual behavior of male rats in adulthood. Behav. Brain Res. 62:119-125; 1994.

14. Houtsmuller, E. J.; Thornton, J.; Slob, A. K.; Rowland, D. L. A multivariate approach to determining the influence of male fetuses on the genital morphology of neonatal female rats. (Submitted).

15. Jackson, J. A.; Albrecht, E. D. Estrogen regulates placental androstenedione production during rat pregnancy. Endocrinology 119(3): 1052-1057; 1986.

16. Ito, S.; Murakami, S.; Yamanouchi, K.; Arai, Y. Prenatal androgen exposure, preoptic area and reproductive functions in the female rat. Brain Dev. 8:463-468; 1986.

17. Krohmer, R. W.; Baum, M. J. Effect of sex, intrauterine position and androgen manipulation on the development of brain aromatase activity in female ferrets. J. Neuroendocrinol. 1:265-271; 1989.

18. Meisel, R. L.; Ward, I. L. Fetal female rats are masculinized by male littermates located caudally in the uterus. Science 213:239-242; 1981.

19. Resko, J. A. Androgen secretion by fetal and neonatal rhesus monkeys. Endocrinology 87:680-687; 1970.

20. Richmond, G.; Sachs, B. D. Further evidence for masculinization of female rats by males located caudally in utero. Horm. Behav. 18:484-490; 1984.

21. Slob, A. K.; Ooms, M. P.; Vreeburg, J. T. M. Prenatal and early postnatal sex differences in plasma and gonadal testosterone and 
plasma luteinizing hormone in female and male rats. J. Endocrinol. $87: 81-87 ; 1980$.

22. Slob, A. K.; den Hanier, R.; Woutersen, P. J. A.; van der Werff ten Bosch, J. J. Prenatal testosterone propionate and postnatal ovarian activity in the rat. Acta Endocr. 103:420-427; 1983

23. Slob, A. K.; van der Schoot, P. Testosterone induced mounting behavior in adult female rats born in litters of different female to male ratios. Physiol. Behav. 28:1007-1010; 1982.

24. Slob, A. K.; Vreeburg, J. T. M. Prenatal androgens in female rats and adult mounting behavior. In: Gilles, R.; Balthazart, J., eds. Neurobiology. Berlin Heidelberg: Springer-Verlag; 1985:165179.

25. Sridaran, R.; Basuray, R.; Gibori, G. Source and regulation of testosterone secretion in pregnant and pseudopregnant rats. Endocrinology 108:855-860; 1981.

26. Tobet, S. A.; Dunlapp, J. L.; Gerall, A. A. Influence of fetal position on neonatal androgen-induced sterility and sexual behavior in female rats. Horm. Behav. 16:251-258; 1982.

27. van de Poll, N. E.; van der Zwan, S. M.; van Ooyen, H. G.; Pater, J. H. Sexual behavior in female rats born in all-female litters. Behav. Brain Res. 4:103-109; 1982.

28. Verjans, H. L.; Cooke, B. A.; de Jong, F. H.; de Jong, C. M. M.; van der Molen, H. J. Evaluation of a radioimmunoassay for testosterone estimation. J. Steroid Biochem. 4:665-676; 1973.

29. Vomachka, A. J.; Lisk, R. D. Androgen and estradiol levels in plasma and amniotic fluid of late gestational male and female hamsters: Uterine position effects. Horm. Behav. 20:181-193; 1986.
30. vom Saal, F. S. Variation in phenotype due to random intrauterine positioning of male and female fetuses in rodents. J. Reprod. Fertil. 62:633-650; 1981.

31. vom Saal, F. S.; Bronson, F. In utero proximity of female house mouse fetuses to males :Effect on reproductive performance during later life. Biol. Reprod. 19:842-853; 1978.

32. vom Saal, F. S.; Bronson, F. Sexual characteristics of adult female mice are correlated with their blood testosterone levels during prenatal development. Science 208:597-599; 1980.

33. Vreeburg, J. T. M.; Groeneveld, J. O.; Post, P. E.; Ooms, M. P. Concentrations of testosterone and androsterone in peripheral and umbilical venous plasma of fetal rats. J. Reprod. Fert. 68:171-175; 1983.

34. Ward, I. L.; Renz, F. J. Consequences of perinatal hormone manipulation on the adult sexual behavior of female rats. J. Comp. Physiol. Psychol. 78:349-355; 1972.

35. Ward, I. L.; Weisz, J. Differential effects of maternal stress on circulating levels of corticosterone, progesterone, and testosterone in male and female rat fetuses and their mothers. Endocrinology 114:1635-1644; 1984.

36. Weisz, J.; Ward, I. L. Plasma testosterone and progesterone titers of pregnant rats, their male and female fetuses and neonatal offspring. Endocrinology 106:81-87; 1980.

37. Zielinski, W. J.; Vandenbergh, J. G. Effect of intrauterine position and social density on age of first reproduction in wild-type female house mice (Mus musculus). J. Comp. Psychol. 105:134-139; 1991.

38. Zielinski, W. J.; Vandenbergh, J. G.; Montano, M. M. Effects of social stress and intrauterine position on sexual phenotype in wild-type house mice (Mus musculus). Physiol. Behav. 49:117-123; 1991. 